Article

\title{
Preparation and Properties of Ginger Essential Oil $\beta$-Cyclodextrin/Chitosan Inclusion Complexes
}

\author{
Yan Zhang *, Hui Zhang, Fang Wang and Li-Xia Wang * \\ Key Laboratory of Food Nutrition and Safety, Ministry of Education, College of Food Engineering and \\ Biotechnology, Tianjin University of Science and Technology, Tianjin 300457, China; \\ 16808963@mail.tust.edu.cn (H.Z.); 884135575@mail.tust.edu.cn (F.W.) \\ * Correspondence: cpzyyan@tust.edu.cn (Y.Z.); lixiawangtust@163.com (L.-X.W.); Tel.: +86-137-5235-3154 (Y.Z.); \\ +86-22-6091-2390 (L.-X.W.)
}

Received: 16 July 2018; Accepted: 28 August 2018; Published: 29 August 2018

check for updates

\begin{abstract}
The ginger essential oil $/ \beta$-cyclodextrin (GEO/ $\beta$-CD) composite, ginger essential oil $/ \beta$ cyclodextrin/chitosan (GEO/ $\beta$-CD/CTS) particles and ginger essential oil/ $\beta$-cyclodextrin/chitosan (GEO/ $\beta$-CD/CTS) microsphere were prepared with the methods of inclusion, ionic gelation and spray drying. Their properties were studied by using scanning electron microscopy (SEM), differential scanning calorimetry (DSC), thermo-gravimetry analysis (TGA), Fourier transform infrared spectroscopy (FT-IR) and X-ray diffraction (XRD). The results showed that the particle size of GEO/ $\beta-C D$ composite was smaller than that of $\beta-C D$ and GEO/ $\beta-C D / C T S$ particles were loose and porous, while the microsphere obtained by spray drying had certain cohesiveness and small particle size. Besides, results also indicated that $\beta$-CD/CTS could modify properties and improve the thermal stability of GEO, which would improve its application value in food and medical industries.
\end{abstract}

Keywords: ginger essential oil (GEO); $\beta$-cyclodextrin ( $\beta-\mathrm{CD})$; chitosan (CTS); microsphere

\section{Introduction}

Ginger (Zingiber officinale RoscoE) possesses various medicinal properties including antioxidant, anti-inflammatory, anticancer and antimicrobial activities and could also be used as a spice in food processing [1-3], which has been widely used in food, medical and cosmetic industries [4]. Its diethyl ether extract contains $95 \%$ of terpenes, including zingiberene, sesquiphellandrene or geranial. However, gingerols and shogaols are the main constituents of hydrophilic extract [5]. As reported, GEO has exhibit strong antimicrobial, antifungal and antioxidant activities [6,7]. Although the medical value of GEO was recognized a long time ago, the study of ginger is still at the primary stage and the deeply processed products of ginger are still not available in Chinese market. Furthermore, analysis of GEO and identification of functional materials need a further survey on the basis of mature extract technology.

Microencapsulation is a technology to package solids, liquids or gaseous materials and the contents in microencapsulation would be released out under specific conditions [8]. Considering many sensitive contents are easily affected by external conditions (e.g., heat, moisture, light and air), the microcapsule technique could effectively protect their structure and bioactivities $[9,10]$. Furthermore, prepared microencapsulation can also change their physicochemical properties [11]. It has been proved that the crosslinked microparticles have a higher thermal stability than the wall material and core material that also exhibit a higher release in simulated intestinal fluid [12]. Therefore, choosing an appropriate encapsulating agent is very important and would be responsible for the quality of microencapsulation. 
Cyclodextrin (CD) is the cyclic oligosaccharide formed by hydrolysis of starch with the action of glucosyltransferase, containing six $(\alpha-C D)$, seven $(\beta-C D)$, or eight $(\gamma-C D) \alpha-1,4$-linked glucopyranose $[13,14]$. There are hydrophilous glycosidic oxygen atoms and hydrophobic hydrogen atoms inside the $\mathrm{CD}$ and it is common that hydrogen atoms cover up the oxygen atoms, leading to a higher hydrophobicity $[15,16]$. Meanwhile, the presence of exterior hydroxyl is responsible for the hydrophilicity outside of CD [17]. So, hydrophobic molecules have access to occupy the cavity of CD, which contributes to the formation of inclusion complex and the size of cavity is responsible for the type of inclusion. The cavity of $\alpha-C D$ is used to include mononuclear aromatics, the cavity of $\beta-C D$ is used to include naphthalene, the cavity of $\gamma-\mathrm{CD}$ is used to include tricyclic aromatic hydrocarbons thanks to the largest size [18]. However, $\beta-C D$ presents a higher stability, rigidity and price advantage, leading to the extensive application of $\beta-C D$ in industry and market. It has been proved that application of $\beta-C D$ increases the solubility of hydrophobic compounds and improves the flavor of bitter substances [19]. Furthermore, as a wall material of microcapsules, $\beta$-CD can improve stability and protect the active ingredients of inclusion.

Chitosan is a potential enhancer of transmucosal drug delivery and has shown many beneficial activities including high biocompatibility, antimicrobial activity [20] and enhancement on the retention time of topically co-administered drugs [21,22]. Besides, Several studies proved that chitosan could increase cell permeability by reversibly affecting paracellular and intracellular pathways of epithelial cells, which might be caused by the binding of positively charged chitosan to the cell membrane [23].

The purpose of the study was evaluating the properties of prepared GEO/ $\beta$-CD composite, GEO/ $\beta$-CD/CTS particles and GEO/ $\beta-C D / C T S$ microsphere by using SEM, FT-IR, XRD, DSC and TGA, which would provide a theoretical basis for their further applications in food and medical industries.

\section{Materials and Methods}

\subsection{Materials}

Essential oil of ginger (Zingiber officinale L., collected from Laiwu, Shandong, China) was extracted by supercritical $\mathrm{CO}_{2}$ extraction (a pressure of 300 bar and a temperature of $47^{\circ} \mathrm{C}$ ) in the Lab. $\beta-\mathrm{CD}$ was obtained from Tianjin Jiangtian Chemical Technology Co., Ltd. (Tianjin, China) and CTS was from Tianjin Chemical Reagent Factory.

\subsection{Preparation of $G E O / \beta-C D$ Composite}

The volume of emulsion was set at $500 \mathrm{~mL}$. $\beta$-CD $(0.5-3.0 \% w / v)$ were prepared separately. A certain amount of $\beta-C D$ was added to the distilled water and the mixture was heated and stirred until the $\beta-C D$ was completely dissolved. Then GEO (half of the $\beta$-CD's mass) was dissolved in anhydrous ethanol. The ethanol solution of GEO was added to the $\beta$-CD solution dropwise, while heated and stirred at $20-70{ }^{\circ} \mathrm{C}$ for $30-180 \mathrm{~min}$.

\subsection{Preparation of $G E O / \beta-C D / C T S$ Particles}

GEO/ $\beta$-CD composite and CTS were mixed (4:3), then $1 \%$ acetic acid was added and stirred for $1 \mathrm{~h}$. Thereafter, the obtained mixture was added to the $6 \%$ sodium tripolyphosphate (STPP) dropwise, followed by washing with distilled water. The obtained wet particles were placed for $24 \mathrm{~h}$ at $-80^{\circ} \mathrm{C}$ and GEO/ $\beta$-CD/CTS particles were prepared by using vacuum freeze-drying technology.

\subsection{Microencapsulation by Spray Drying}

The process of spray drying was conducted for the emulsions obtained in Sections 2.2 and 2.3. The feed emulsions were dried by using a spray-dryer (Shanghai Pilotech Instrument Equipment Co., Ltd., Shanghai, China) equipped with a two-fluid nozzle atomizer. The following operational conditions were used, as described in previous studies: inlet temperature of $120^{\circ} \mathrm{C}$, outlet temperature 
of $80{ }^{\circ} \mathrm{C}$ and feed rate of $0.8 \mathrm{~L} \cdot \mathrm{h}^{-1}$. The atomizing air flow was kept in $35 \mathrm{~L} \cdot \mathrm{min}^{-1}$. The dried powder was collected and stored in opaque airtight containers at $4{ }^{\circ} \mathrm{C}$ for further analysis.

\subsection{Characterization of the Microencapsulation}

\subsubsection{Determine of Encapsulation Efficiency}

GEO in the microparticles was determined as described by Li et al [24] with certain modifications. sample of $1000 \mathrm{mg}$ was dissolved in $20 \mathrm{~mL}$ distillate water at $45{ }^{\circ} \mathrm{C}$ in glass tubes assisted by ultrasound at $160 \mathrm{~W}$ of nominal power (Branson Digital Sonifier ${ }^{\circledR}$, Model S-450D, Branson Ultrasonics Corporation, Danbury, CT, USA), followed by the addition and mixture with $10 \mathrm{~mL}$ hexane for $1 \mathrm{~min}$. Essential oil was extracted with hexane by heating the sample in glass tubes at $45^{\circ} \mathrm{C}$ in a water bath with intermittent mixing during $30 \mathrm{~min}$. The tubes were cooled to room temperature and hexane was separated from the aqueous phase by centrifuging at $3000 \mathrm{rpm}$ for $5 \mathrm{~min}$. The extraction was repeated four times. The absorbance was measured at $232 \mathrm{~nm}$ by using a UV-Vis spectrophotometer (Bel Photonics, Piracicaba, Brazil) and expressed as the amount of GEO in hexane. The concentration was calculated by using a calibration curve and the encapsulation efficiency (EE) was determined using the following formula:

$$
E E(\%)=M / M_{0} \times 100
$$

where $M$ is the amount (mg) of oil in microparticles and $M_{0}$ is the initial oil amount (mg) added to the emulsion.

\subsubsection{Scanning Electron Microscopy (SEM)}

The external structures of microcapsules were examined by SEM (SU-1510, HITACHI Ltd., Tokyo, Japan). Microcapsules were placed on the SEM stub mounts by using double sided adhesive tape, coated with a layer of gold $(40-50 \mathrm{~nm})$ and analyzed with a $5.0 \mathrm{kV}$ acceleration voltage.

\subsubsection{Fourier Transform Infrared Spectroscopy (FT-IR)}

The infrared spectroscopic analysis was performed by using a Fourier transform infrared spectroscopy (Vector 22, Brooke Spectrometer Company, Karlsruhe, Germany). Briefly, a certain amount of sample was mixed with $\mathrm{KBr}$ and was fully ground. Then the obtained mixture was tableted by using a pressure machine, followed by scanning with an infrared spectrometer. The scanning wavelength ranged from 400 to $4000 \mathrm{~cm}^{-1}$ and the resolution ratio was $4 \mathrm{~cm}^{-1}$.

\subsubsection{X-ray Diffraction (XRD)}

The physicochemical properties were analyzed by using an X-ray diffractometer (TD-3500, Tongda Instrument Co., Ltd., Dandong, China). Briefly, a certain amount of powder sample was poured into grooves and compacted. The analysis was made by using Cu-K1 radiation with a wavelength of $1.54 \AA$ at $30 \mathrm{kV}$ and $30 \mathrm{~mA}$. Samples were analyzed at angles from $4^{\circ}$ to $40^{\circ}$ in $2 \mathrm{~h}$ with an increment of $0.02^{\circ}$ $\left(1.2^{\circ} \mathrm{min}^{-1}\right)$ as described by Botrel et al. [25].

\subsubsection{Thermo-Gravimetry Analysis (TGA)}

Thermo-gravimetric (mass loss) and derivative thermo-gravimetric (dTG) curves were obtained by using a TGA50H thermobalance (Corporation Shimadzu, Kyoto, Japan). Samples of $5 \mathrm{mg}-7 \mathrm{mg}$ were used for the experiment and the analysis was conducted under the following operating conditions: dynamic nitrogen atmosphere with flow of $20 \mathrm{~mL} / \mathrm{min}$, heating rate: $10^{\circ} \mathrm{C} / \mathrm{min}$ and temperature range: $50-550{ }^{\circ} \mathrm{C}$. 


\subsubsection{Differential Scanning Calorimetry (DSC)}

The thermal properties were analyzed by using a differential scanning calorimeter (DSC204F1, Netzsch Scientific Instrument Trading Co., Ltd., Selb, Germany). $2.5 \mathrm{mg}$ of samples was put into a crucible and pressed. The analysis was conducted under the following operating conditions: initial temperature: room temperature, final temperature: $200^{\circ} \mathrm{C}$ and heating rate: $10^{\circ} \mathrm{C} / \mathrm{min}$.

\subsubsection{Statistical Analysis}

All values were presented as the mean \pm standard deviation (S.D.) of three independent experiments performed in triplicate and statistically analyzed using SPSS for windows (version 19.0, SPSS Inc., Chicago, IL, USA).

\section{Results and Discussion}

\subsection{Effect of Different Conditions to Prepare GEO/ $\beta$-CD Composite}

The effects of different core-wall ratios to prepare GEO/ $\beta$-CD composite were carried out in the core-wall ratio range from 1:3 to 1:8 (Figure 1A). With the increase of $\beta-C D$, the encapsulation efficiency increased initially, reached maximum and then decreased, which demonstrated that the core-wall ratio of 1:5 was suitable to prepare GEO/ $\beta$-CD composite.

The concentrate of wall material was varied from $0.5 \%$ to $3 \%$ (Figure 1B). With the increase of wall material concentration, encapsulation efficiency increased initially and then decreased. For a higher concentration of wall material $(2.0 \%$ and $2.5 \%)$, more water was occupied in the cavity of $\beta-C D$, leading to the decreased GEO in the cavity. Therefore, the optimum wall material concentration was selected as $2.0 \%$.
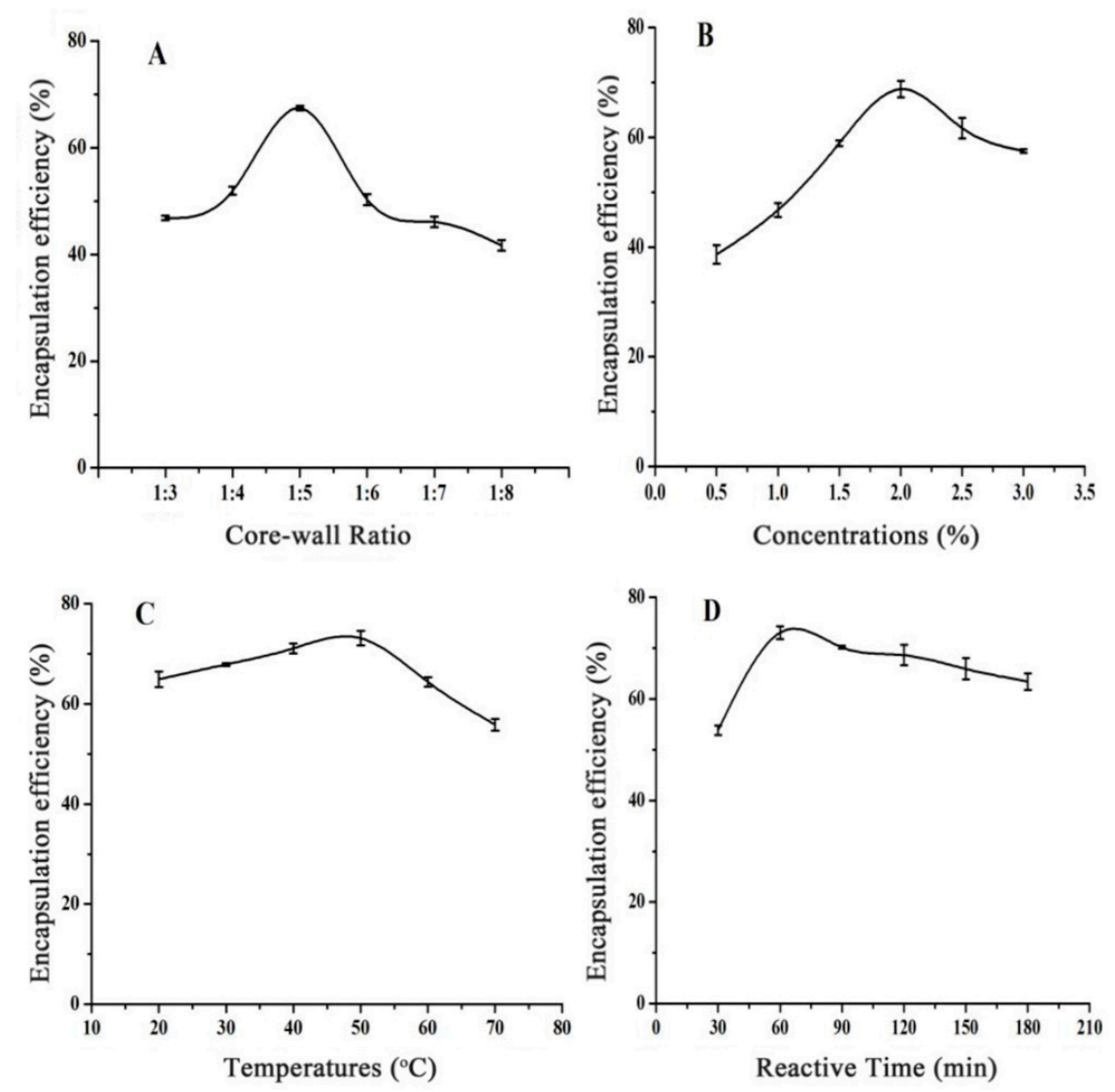

Figure 1. Effects of different conditions to prepare ginger essential oil (GEO)/ $\beta$-CD composite: (A) Core-wall ratio; (B) Wall material concentration; (C) Temperature; (D) Reactive time. 
The effects of different temperatures on the encapsulation efficiency were shown in Figure 1C. With the increase of temperature, encapsulation efficiency increased initially, reached maximum value and then decreased. Therefore, the encapsulation efficiency at $50{ }^{\circ} \mathrm{C}$ was higher than others.

GEO/ $\beta$-CD composites were prepared using six different reactive times (Figure 1D). With the increase of reactive time, encapsulation efficiency increased initially and when the time reached $60 \mathrm{~min}$, the encapsulation efficiency decreased, which showed that the encapsulation efficiency of $60 \mathrm{~min}$ was chosen for further experiments.

\subsection{Encapsulation Efficiency}

The GEO/ $\beta$-CD composite was prepared by using the following conditions. The core wall ratio was 1:5 and the concentration of wall material was $2.0 \%$. The encapsulation efficiency of GEO was calculated by using the formula shown in Section 2.5.1, which demonstrated that the encapsulation efficiency of prepared GEO/ $\beta$-CD composite was $72.02 \% \pm 1.46 \%$.

\subsection{Scanning Electron Microscopy (SEM)}

As shown in Figure 2, the SEM photographs of $\beta-C D$ and GEO/ $\beta-C D$ composite were presented in $A$ and $B$. The results showed that the particle size of GEO/ $\beta-C D$ composite was smaller than that of $\beta-C D$ and the particles of the former had obvious aggregation, while the internal structures of $\beta-C D$ and GEO/ $\beta-C D$ composite were dense, which indicated that $\beta-C D$ changed its physicochemical properties thanks to the inclusion with GEO. $\beta-C D$ was separated from aqueous solution during the process of inclusion, which contributes to the aggregation.

The dry product of GEO/ $\beta$-CD/CTS particles was prepared by using the vacuum freeze-drying technology, leading to the folded surface and porous internal structure. The SEM photographs of the dry product were presented in C. It revealed that both surfaces of particles and its internal structure were porous and loose. Meanwhile, the structure was different from that of GEO/ $\beta$-CD composite, which deduced that ionic polymerization of CTS and STPP adsorbed GEO/ $\beta$-CD composite.

The results in D revealed that the GEO/ $\beta$-CD/CTS microsphere had a much smaller particle size than GEO/ $\beta$-CD/CTS particles. The microsphere had a folded surface and poorer aggregation, which was different from the structure of GEO/ $\beta-C D$ composite. It declared that there was a crosslinking reaction between $\mathrm{GEO} / \beta-\mathrm{CD}$ composite and CTS.
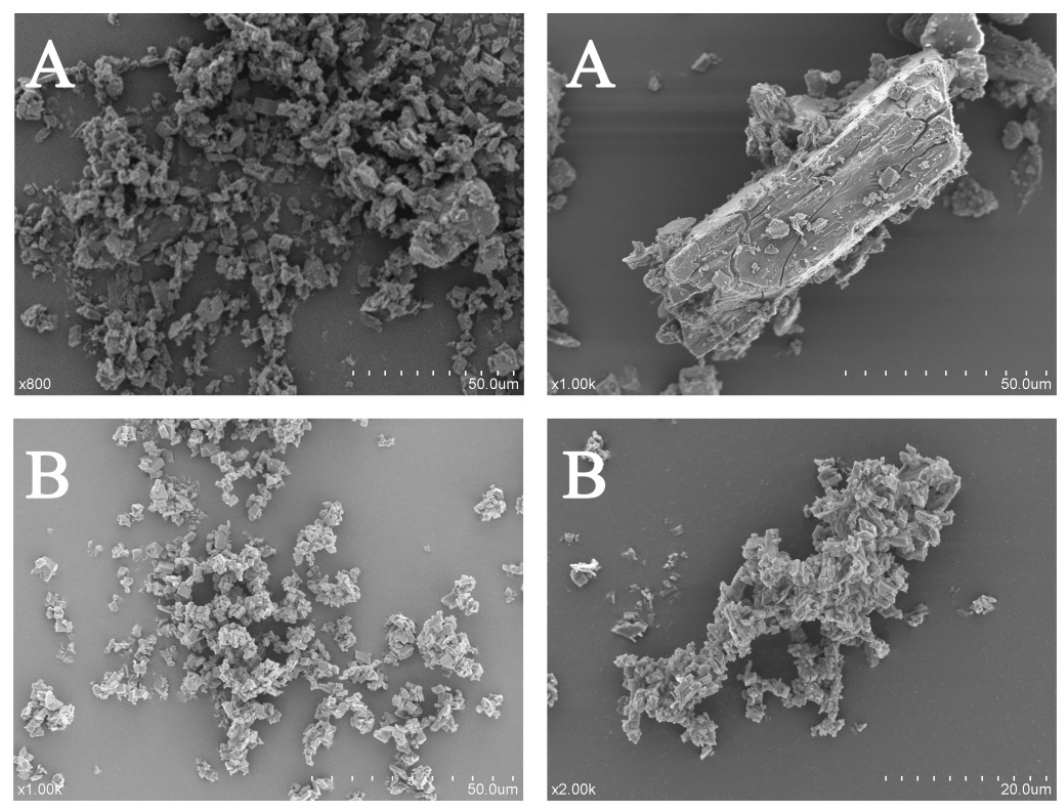

Figure 2. Cont. 

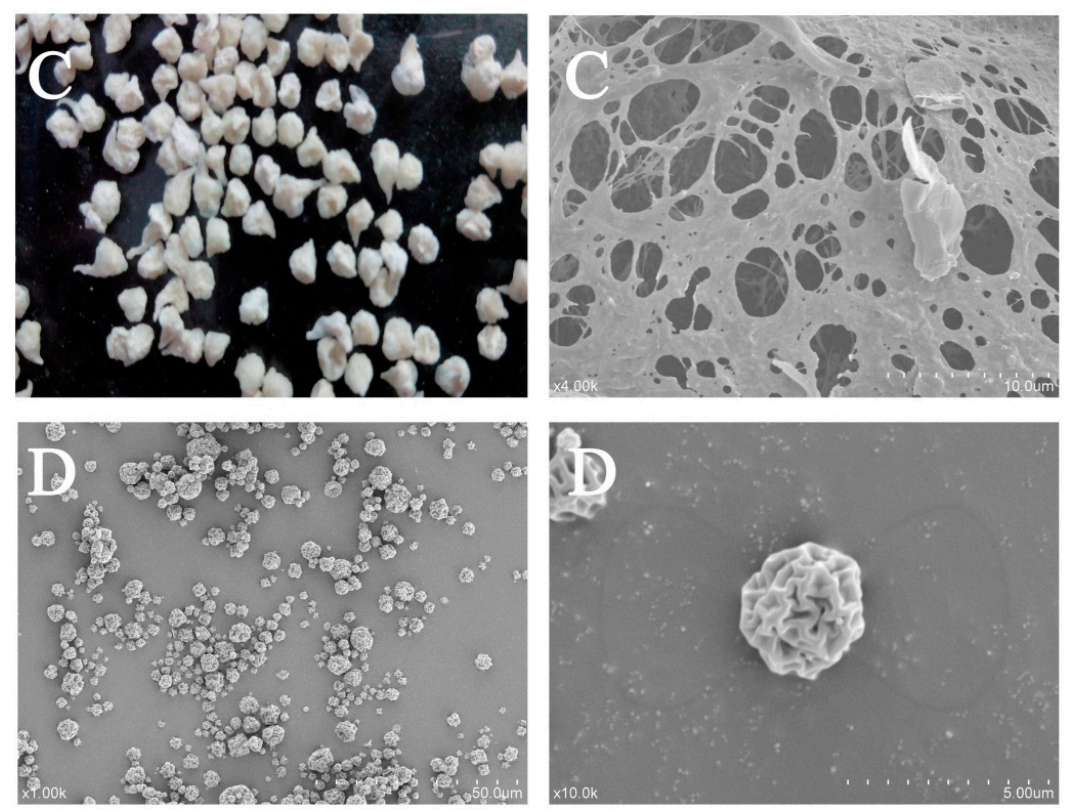

Figure 2. Scanning electron microscopy (SEM) photographs of different materials: (A) $\beta-C D$; (B) GEO/ $\beta$-CD composite; (C) GEO/ $\beta$-CD/CTS particles; (D) GEO/ $\beta$-CD/CTS microsphere.

\subsection{Fourier Transform Infrared Spectral (FT-IR)}

The infrared spectra were presented in Figure 3. It was exhibited that $\beta-C D$ had an absorption peak at $3385.90 \mathrm{~cm}^{-1}$, corresponding to the stretching vibration of $-\mathrm{OH}$. The GEO/ $\beta-\mathrm{CD}$ composite had a red shift of $-\mathrm{OH}$ stretching vibration absorption peak but $\beta-\mathrm{CD}$ did not, which appeared at $3373.64 \mathrm{~cm}^{-1}$. GEO/ $\beta-C D$ composite also had a red shift of $>\mathrm{CH}-$ and $-\mathrm{CH}_{2}-$ stretching vibration absorption peak compared with $\beta-C D, 2923.63 \mathrm{~cm}^{-1}$ and $2925.78 \mathrm{~cm}^{-1}$ with a stronger intensity of the peak. Meanwhile, the absorption peaks at $1414-1335 \mathrm{~cm}^{-1}, 1156-1028 \mathrm{~cm}^{-1}$ and $756-530 \mathrm{~cm}^{-1}$ corresponded to flexural vibration of $\mathrm{C}-\mathrm{O}-\mathrm{H}(\mathrm{C}-\mathrm{C}-\mathrm{H})$, stretching vibration of $\mathrm{C} / \mathrm{C}, \mathrm{O}, \mathrm{H}$ as well as vibrational mode of intramolecular cyclization and framework, respectively, which all had a red shift in the infrared spectra of GEO/ $\beta-C D$ composite [26]. It was deduced that there was an inclusion reaction between GEO and $\beta-C D$. However, the composite had a blue shift of $>C=O$ stretching vibration absorption peak compared with $\beta-C D, 1639.35 \mathrm{~cm}^{-1}$ and $1636.98 \mathrm{~cm}^{-1}$ with a weaker intensity of the peak, demonstrating formation of the composite. As shown in Figure 3, there was no significant difference between the characteristic absorption peaks of $\beta-\mathrm{CD}$ and the composite. The guest molecules were included in hydrophobic cavity and its content was less than $25 \%$. Thus the characteristic absorption peaks of guest molecules were covered by that of $\beta-C D$, leading to the difficulty to identify [27].

The results in $\mathrm{B}, \mathrm{C}, \mathrm{D}$ and $\mathrm{E}$ indicated that the infrared spectra of physical mixture (with STPP) were superimposed by the characteristic absorption peaks of GEO/ $\beta$-CD composite, CTS and STPP. The absorption peaks at $3373.54 \mathrm{~cm}^{-1}, 2923.71 \mathrm{~cm}^{-1}$ and $1640.64 \mathrm{~cm}^{-1}$ presented stretching vibration of $-\mathrm{OH},>\mathrm{CH}-,-\mathrm{CH}_{2}-$ and $>\mathrm{C}=\mathrm{O}$ in the infrared spectra of physical mixture (with STPP). Its characteristic vibration peaks at $500-1500 \mathrm{~cm}^{-1}$ were similar to that of $\mathrm{GEO} / \beta-\mathrm{CD}$ composite [28]. Compared with physical mixture (with STPP), GEO/ $\beta$-CD/CTS particles had $=\mathrm{CH}_{2}$ symmetric stretching vibration peak at $2852.75 \mathrm{~cm}^{-1}$ and $-\mathrm{CH}_{3}$ variable angle vibration peak at $1456.89 \mathrm{~cm}^{-1}$ but without the (C-N) stretching vibration peak at $1247.06 \mathrm{~cm}^{-1}$. Meanwhile, it had a blue shift of -OH characteristic absorption peak compared with physical mixture (with STPP), $3416.65 \mathrm{~cm}^{-1}$ and $3373.54 \mathrm{~cm}^{-1}$, respectively. It was deduced that GEO/ $\beta-C D / C T S$ particles had fracture and formation of bonds. It also further confirmed that there was a crosslinking reaction among CTS, STPP and GEO/ $\beta$-CD composite instead of physical mixture. 


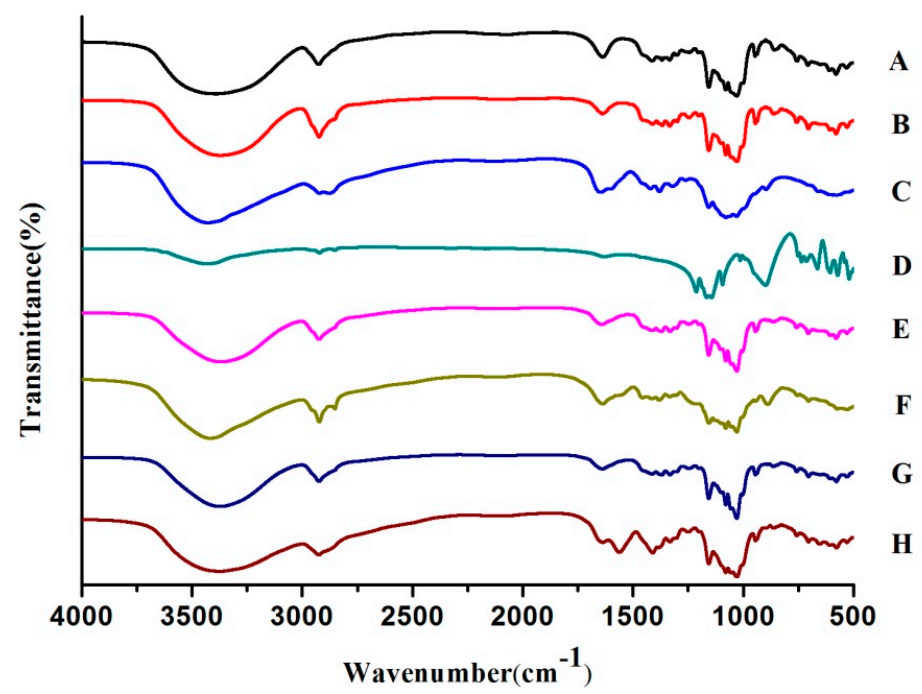

Figure 3. Fourier transform-infrared (FT-IR) spectra of different materials. A: $\beta-C D ; B: G E O / \beta-C D$ composite; C: Chitosan; D: sodium tripolyphosphate (STPP); E: Physical mixture (with STPP); F: GEO/ $\beta$-CD/CTS particles; G: Physical mixture (without STPP); H: GEO/ $\beta$-CD/CTS microsphere.

The photograph shown in $\mathrm{H}$ represented the infrared spectrum of GEO/ $\beta$-CD/CTS microsphere. The absorption peaks at $3373.87 \mathrm{~cm}^{-1}, 2924.14 \mathrm{~cm}^{-1}$ and $1637.11 \mathrm{~cm}^{-1}$ presented stretching vibration of $-\mathrm{OH},>\mathrm{CH}-$ and $-\mathrm{CH}_{2}-$ as well as $>\mathrm{C}=\mathrm{O}$ in the infrared spectrum of microsphere. Its characteristic vibration peaks at $500-1500 \mathrm{~cm}^{-1}$ were similar to that of GEO/ $\beta-C D$ composite but the former was more gentle because of the fewer characteristic peaks of CTS and its weaker intensity, leading to the covered by GEO/ $\beta$-CD composite [29]. Compared with the infrared spectrum of physical mixture (without STPP), the microsphere did not have a red shift but the intensities of its vibration peaks have strengthened. And it had a CNH vibration peak at $1560.61 \mathrm{~cm}^{-1}$. It was deduced that $\mathrm{GEO} / \beta-\mathrm{CD} / \mathrm{CTS}$ microsphere was different from physical mixture (without STPP). Furthermore, it confirmed that there was a crosslinking reaction between CTS and GEO/ $\beta-\mathrm{CD}$ composite in the microsphere.

\subsection{X-ray Diffraction (XRD)}

As shown in Figure 4, the XRD patterns of $\beta-C D$ and GEO/ $\beta-C D$ composite are presented in $A$ and $B$, which reveal the crystal structures of $\beta-C D$ and its composite. As shown, both $\beta-C D$ and GEO/ $\beta-C D$ composite had apparent crystal structures but there were significant differences between the two. $\beta$-CD had apparent diffraction peaks at $9.06^{\circ}, 12.67^{\circ}, 22.77^{\circ}, 27.17^{\circ}$ and $34.90^{\circ}$, while GEO $/ \beta-C D$ composite had apparent diffraction peaks at $6.61^{\circ}, 11.59^{\circ}, 17.37^{\circ}, 17.97^{\circ}$ and $20.79^{\circ}$ but without the above peaks of $\beta-C D$ and the intensities of its diffraction peaks at $17.37^{\circ}$ and $17.97^{\circ}$ were stronger than that of $\beta$-CD. Meanwhile, GEO/ $\beta$-CD composite had no diffraction peaks after $25^{\circ}$, which was also different from $\beta$-CD. It confirmed that GEO and $\beta$-CD formed a composite, which changed the crystalline properties of $\beta-C D$.

The XRD patterns also revealed that both GEO/ $\beta$-CD composite and STPP had apparent crystal structures, while CTS had amorphous structures, so the physical mixture (with STPP) presented crystal structures with certain amorphous structures [30]. CTS had a wider diffraction peak at $19.56^{\circ}$, while STPP had diffraction peaks at $18.86^{\circ}, 19.39^{\circ}, 19.87^{\circ}, 29.68^{\circ}, 32.49^{\circ}, 33.33^{\circ}, 34.15^{\circ}, 34.59^{\circ}$ and $36.60^{\circ}$. Meanwhile, the XRD peaks of physical mixture (with STPP) were superimposed by that of GEO/ $\beta-C D$ composite, CTS and STPP. However, the diffraction peaks of GEO/ $\beta$-CD/CTS particles were different from physical mixture (with STPP), which appeared at $6.74^{\circ}, 11.71^{\circ}$ and $17.59^{\circ}$. GEO/ $\beta-\mathrm{CD} / \mathrm{CTS}$ particles also presented an apparent amorphism. It was deduced that GEO/ $\beta-\mathrm{CD} / \mathrm{CTS}$ particles were different from physical mixture (with STPP) and there was a crosslinking reaction in the process of preparation, leading to the changes of crystalline properties. 
The photograph shown in $\mathrm{H}$ represented the XRD patterns of GEO/ $\beta-\mathrm{CD} / \mathrm{CTS}$ microsphere. It indicated that the mixture prepared by GEO/ $\beta-\mathrm{CD}$ composite and CTS presented crystal structures with certain amorphous structures [31]. The diffraction peaks of GEO/ $\beta$-CD/CTS microsphere were apparently different from the physical mixture (without STPP). The intensity of its diffraction peak at $11.84^{\circ}$ was weaker than that of physical mixture (without STPP), while the intensity of diffraction peak at $17.53^{\circ}$ was stronger. Meanwhile, the microsphere formed a new diffraction peak at $18.68^{\circ}$ but without the diffraction peaks at $17.82^{\circ}$ and $20.66^{\circ}$. It was deduced that crystalline properties of the microsphere changed during the process of spray drying.

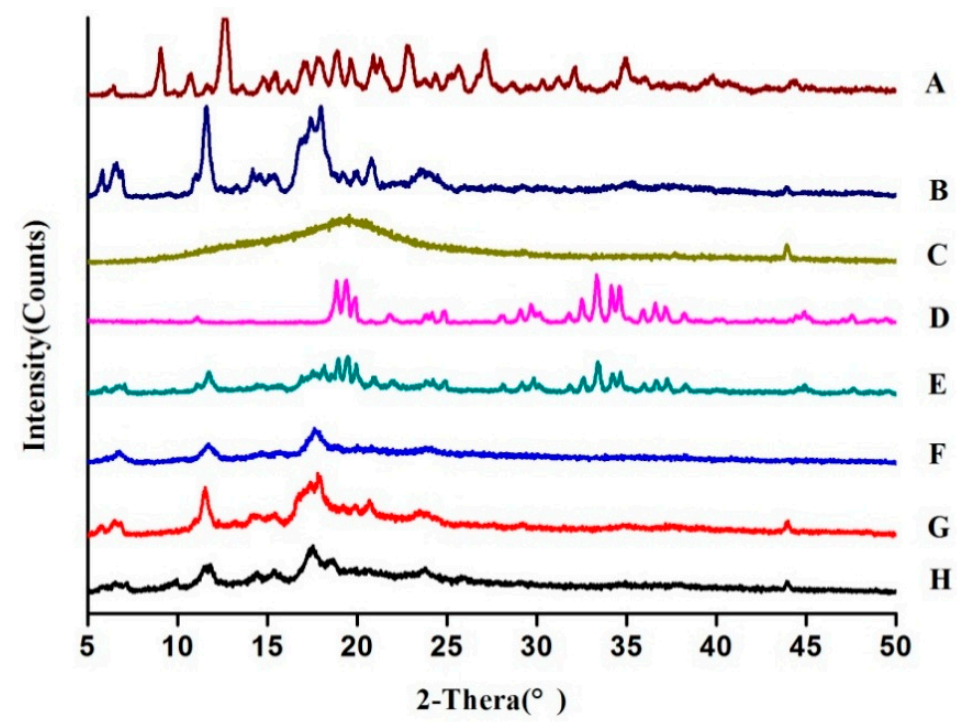

Figure 4. X-ray diffraction (XRD) patterns of different materials. A: $\beta-C D ; B: G E O / \beta-C D$ composite; C: Chitosan; D: STPP; E: Physical mixture (with STPP); F: GEO/ $\beta$-CD/CTS particles; G: Physical mixture (without STPP); H: GEO/ $\beta-\mathrm{CD} / \mathrm{CTS}$ microsphere.

\subsection{Thermogravimetric Analysis (TGA)}

The TGA spectra of $\beta-C D$ and its complexes were expressed in Figure 5 . As shown, $\beta-C D$ had two stages of weight loss. The first stage of the thermal weight loss was from room temperature to final temperature $\left(108.58^{\circ} \mathrm{C}\right)$. The weight-loss rate was $12.52 \%$ and the temperature of maximum weight-loss rate was $79.09^{\circ} \mathrm{C}$. The second was the stage of apparent thermal weight loss. The initial temperature was $260.58^{\circ} \mathrm{C}$. The final temperature was $409.18^{\circ} \mathrm{C}$. The weight-loss rate reached $76.2 \%$ and the temperature of maximum weight-loss rate was $321.27^{\circ} \mathrm{C}$. The TGA spectrum of GEO/ $\beta-\mathrm{CD}$ composite was different from that of $\beta$-CD. It had two successive stages of weight loss. The first stage of the thermal weight loss was from $27.02{ }^{\circ} \mathrm{C}$ to $134.10^{\circ} \mathrm{C}$ and the weight-loss rate reached $9.06 \%$. The second was the stage of apparent thermal weight loss. The initial temperature was 249.81 ${ }^{\circ} \mathrm{C}$. The final temperature was $400.11{ }^{\circ} \mathrm{C}$. The weight-loss rate reached $78.59 \%$ and the temperature of maximum weight-loss rate was $321.27^{\circ} \mathrm{C}$. At the first stage of weight loss, $\beta$-CD had the losses of internal water and absorbed water. But when the temperature reached $108{ }^{\circ} \mathrm{C}$, there was no weight loss in $\beta-C D$, while GEO/ $\beta$-CD composite still had a weight loss with increased temperature thanks to the thermal protection of $\beta-C D$. At the second stage of weight loss, the weight-loss rate and temperature of maximum weight-loss rate of GEO/ $\beta-C D$ composite were the same as $\beta-C D$, because $\beta-\mathrm{CD}$ had a thermal degradation with the production of $\mathrm{CO}_{2}, \mathrm{CO}$ and $\mathrm{H}_{2} \mathrm{O}$. Meanwhile, the initial temperature and final temperature of the GEO/ $\beta-C D$ composite were lower than that of $\beta-C D$, which illustrated that the clathration of $\beta-C D$ changed its thermal properties and $\beta-C D$ exhibited a thermal protection for GEO. 
The thermogravimetric analysis of GEO/ $\beta-\mathrm{CD} / \mathrm{CTS}$ particles was shown in F of Figure 5. The results revealed that GEO/ $\beta-C D$ composite had the apparent thermal weight loss. When the temperature reached $595.76^{\circ} \mathrm{C}$, the amount of residue was $7.222 \%$. STPP exhibited a stronger thermal stability and its weight loss was $1.592 \%$ from room temperature to $595.75{ }^{\circ} \mathrm{C}$. At the first stage of weight loss, the weight-loss rate of GEO/ $\beta-\mathrm{CD} / \mathrm{CTS}$ particles was lower than that of physical mixture (with STPP). At the second stage of weight loss, both GEO/ $\beta$-CD/CTS particles and physical mixture (with STPP) exhibited a severe decomposition and higher thermal weight loss. Meanwhile, physical mixture (with STPP) had higher weight-loss rate, lower temperature of maximum weight-loss rate, lower initial temperature and final temperature than that of GEO/ $\beta-C D / C T S$ particles thanks to the formed covalent bond between CTS and STPP. The covalent bond was not destroyed easily with increased temperature, while the three materials in physical mixture (with STPP) all had a loss and decomposition during the whole process. GEO/ $\beta$-CD/CTS particles had a lower weight-loss rate than that of GEO/ $\beta-C D$ composite from room temperature to $200{ }^{\circ} \mathrm{C}$, which indicated that ionic gelation changed the thermal properties of the particles and GEO/ $\beta-\mathrm{CD} / \mathrm{CTS}$ particles had a thermal protection for GEO.

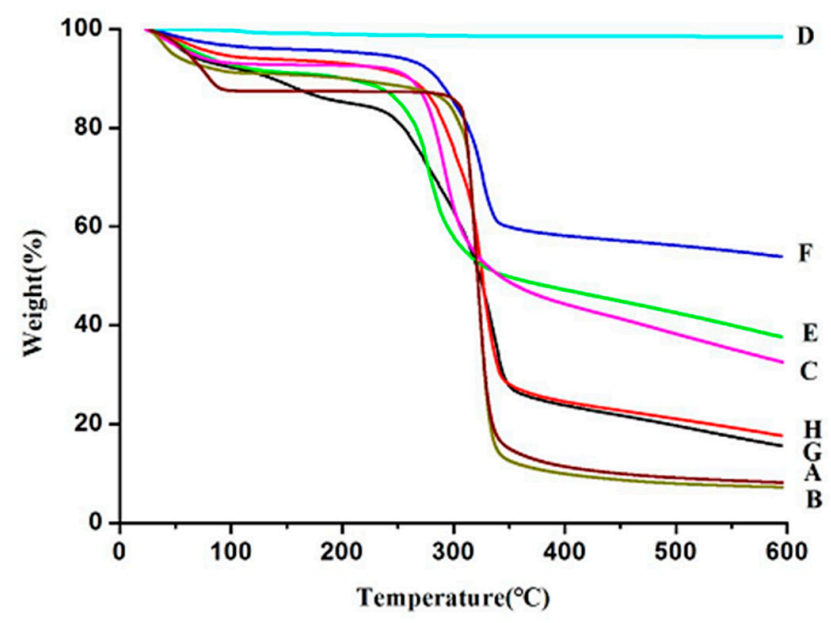

Figure 5. Thermogravimetric analysis (TGA) spectra of different materials. A: $\beta-C D ; B: G E O / \beta-C D$ composite; C: Chitosan; D: STPP; E: Physical mixture (with STPP); F: GEO/ $\beta$-CD/CTS particles; G: Physical mixture (without STPP); H: GEO/ $\beta-\mathrm{CD} / \mathrm{CTS}$ microsphere.

The results also revealed that the GEO/ $\beta-\mathrm{CD} / \mathrm{CTS}$ microsphere had two stages of weight loss. The first stage of the thermal weight loss was from room temperature to $219.18^{\circ} \mathrm{C}$ and the weight-loss rate was $6.01 \%$. The second was the stage of apparent thermal weight loss. The initial temperature was $219.18{ }^{\circ} \mathrm{C}$. The final temperature was $417.69^{\circ} \mathrm{C}$. The weight-loss rate reached $68.64 \%$ and the temperature of maximum weight-loss rate was $324.67^{\circ} \mathrm{C}$. The physical mixture (without STPP) had also two stages of weight loss. The first stage of the thermal weight loss was from room temperature to $207.27^{\circ} \mathrm{C}$ and the weight-loss rate was $15.01 \%$. The second was the stage of apparent thermal weight loss. The initial temperature was $207.27^{\circ} \mathrm{C}$. The final temperature was $400.11^{\circ} \mathrm{C}$. The weight-loss rate reached $61.16 \%$ and the temperature of maximum weight-loss rate was $336.58^{\circ} \mathrm{C}$. At the first stage of weight loss, GEO/ $\beta$-CD/CTS microsphere presented a lower weight-loss rate than that of physical mixture (without STPP). It was due to the formation of chemical bond between GEO/ $\beta$-CD composite and CTS, which was not destroyed easily with the increased temperature. When the temperature reached $325^{\circ} \mathrm{C}$, the spectrum of GEO/ $\beta$-CD/CTS microsphere was similar to that of physical mixture (without STPP) thanks to the decomposition of CTS and $\beta$-CD. However, the microsphere had a lower weight-loss rate than that of GEO/ $\beta$-CD composite before $125{ }^{\circ} \mathrm{C}$. It was deduced that there was a formation of chemical bond between GEO/ $\beta$-CD composite and CTS by spray drying and $\mathrm{GEO} / \beta-\mathrm{CD} / \mathrm{CTS}$ microsphere had a thermal protection for GEO. 


\subsection{Differential Scanning Calorimetry (DSC)}

The changes of DSC absorption peaks can be used to judge the formation of composite. The enthalpy of A-H was $-331.18 \mathrm{~J} / \mathrm{g},-199.20 \mathrm{~J} / \mathrm{g},-178.94 \mathrm{~J} / \mathrm{g},-15.63 \mathrm{~J} / \mathrm{g},-146.51 \mathrm{~J} / \mathrm{g},-212.47 \mathrm{~J} / \mathrm{g}$, $-182.72 \mathrm{~J} / \mathrm{g}$ and $-300.26 \mathrm{~J} / \mathrm{g}$, respectively. The thermograms of $\beta-\mathrm{CD}$ and GEO $/ \beta-\mathrm{CD}$ composite are presented in $\mathrm{A}$ and $\mathrm{B}$ of Figure 6. As shown, $\beta$-CD had an absorption peak at $113.65^{\circ} \mathrm{C}$, corresponding to the dehydration in the cavity of $\beta-C D$ and the enthalpy was $-331.18 \mathrm{~J} / \mathrm{g}$. The absorption peaks of GEO/ $\beta$-CD composite had an apparent shift and its enthalpy was reduced significantly. Meanwhile, the final temperature of GEO/ $\beta-C D$ composite was higher than that of $\beta-C D$. It revealed that the guest molecules changed or were replaced, which was responsible for the formation of composite and the protection for guest molecules was strengthened. It can be deduced that the water presented in the cavity of $\beta-C D$ was replaced with GEO, leading to the formation of GEO/ $\beta-C D$ composite and the thermal stability was strengthened.

The thermograms of physical mixture (with STPP) and GEO/ $\beta-\mathrm{CD} / \mathrm{CTS}$ particles were shown in $\mathrm{E}$ and $\mathrm{F}$ of Figure 6. The results revealed that physical mixture (with STPP) had an absorption peak at $200{ }^{\circ} \mathrm{C}$ and its enthalpy was $-146.51 \mathrm{~J} / \mathrm{g}$, while the enthalpy of GEO/ $\beta-\mathrm{CD} / \mathrm{CTS}$ particles was $-212.47 \mathrm{~J} / \mathrm{g}$. It demonstrated that covalent bond was formed by the reaction of CTS and STPP and the covalent bond was more stable than ionic bond. So, GEO/ $\beta$-CD/CTS particles had a higher enthalpy with increased temperature, leading to the improvement of thermal stability.

The results in $\mathrm{G}$ and $\mathrm{H}$ of Figure 6 revealed that GEO/ $\beta-\mathrm{CD} / \mathrm{CTS}$ microsphere had a higher enthalpy than that of physical mixture (without STPP), $-300.26 \mathrm{~J} / \mathrm{g}$ and $-182.72 \mathrm{~J} / \mathrm{g}$, respectively. It declared that spray drying changed the combination mode between CTS and $\beta-C D$ and the covalent bond was formed during the process of heating and cooling, which presented a stronger thermal stability. It also certified that GEO/ $\beta$-CD/CTS microsphere was prepared with the method of spray drying and the particles had certain stability.

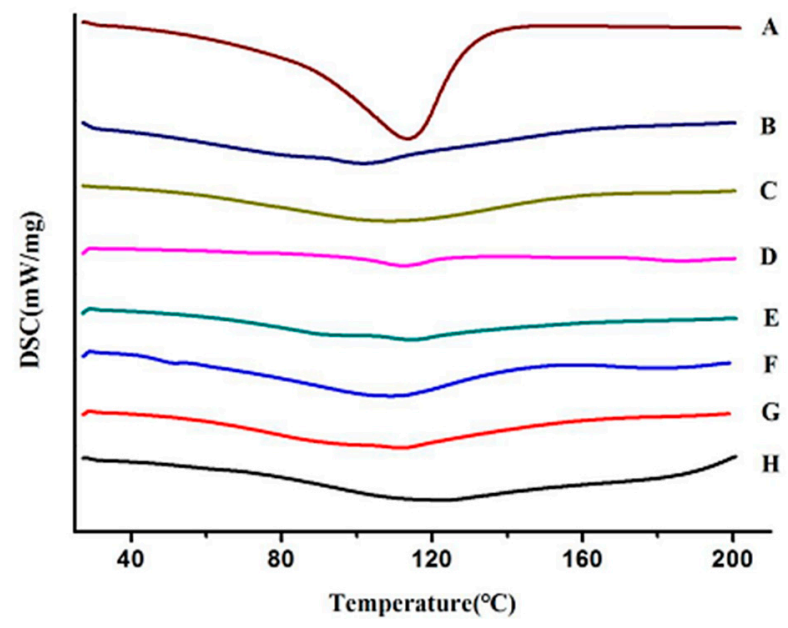

Figure 6. Thermograms of different materials. A: $\beta-C D ; B: G E O / \beta-C D$ composite; $C$ : Chitosan; D: STPP; E: Physical mixture (with STPP); F: GEO/ $\beta-C D / C T S$ particles; G: Physical mixture (without STPP); $\mathrm{H}: \mathrm{GEO} / \beta-\mathrm{CD} / \mathrm{CTS}$ microsphere.

\section{Discussion}

$\beta-C D$ can be utilized in foods mainly carrying flavors and other sensitive ingredients through molecular encapsulation [32] and has the ability to establish specific interactions with various types of molecules [33]. Essential oil, a plant-derived bioactive substance, has exhibited various bioactivities including antimicrobial [34], antioxidant [35] and antitumor activities [36]. As reported, the structure and activity of essential oil would be strengthened after encapsulated by $\beta-C D[37,38]$, thus we prepared $\beta-C D$ and $\mathrm{GEO} / \beta-\mathrm{CD}$ composite and researched their physicochemical properties in 
the experiment. It was found that GEO/ $\beta-C D$ composite had a smaller particle size and certain aggregation. The results shown in the FT-IR spectra revealed that GEO/ $\beta$-CD composite had a red shift of characteristic vibration absorption peaks compared with $\beta-C D$ and it formed a new stretching vibration absorption peak. Meanwhile, the intensities of stretching vibration absorption peaks also changed. As shown in the XRD patterns, compared with $\beta-C D, G E O / \beta-C D$ composite had the disappearance and formation of diffraction peaks and the intensities changed. The results presented in the TGA spectra indicated that the clathration of $\beta-C D$ changed its thermal properties and $\beta-C D$ exhibited a thermal protection for GEO. And the results in the thermograms demonstrated that the water presented in the cavity of $\beta-C D$ was replaced with GEO and GEO/ $\beta-C D$ composite exhibited a thermal protection for GEO, which were consistent with previous studies $[39,40]$.

As is known to us, CTS is widely used encapsulate material because of its biocompatibility and low toxicity, besides, it can also produce different forms of nanomaterials [41,42], $\beta$-CD modified chitosan ( $\beta$-CD/CTS) system could effectively control release of essential oil [43]. In the present study, we prepared GEO/ $\beta-\mathrm{CD} / \mathrm{CTS}$ particles and GEO/ $\beta-\mathrm{CD} / \mathrm{CTS}$ microsphere by ionic gelation and spray drying methods respectively. Results indicated that they both had a higher enthalpy than that of physical mixture (with STPP), leading to a stronger thermal stability, which indicated that CTS could modify the properties of GEO/ $\beta-\mathrm{CD}$ and improve the thermal stability.

\section{Conclusions}

The GEO/ $\beta$-CD composite, GEO/ $\beta$-CD/CTS particles and GEO/ $\beta$-CD/CTS microsphere were prepared and their properties were investigated via SEM, DSC, TGA, FT-IR and XRD methods in this study. The results showed that $\beta$-CD/CTS could modify properties and improve the thermal stability of GEO, leading to the higher water solubility and lower volatility, which indicated that $\beta-C D / C T S$ composite would exhibit better application value in food and medical industry.

Author Contributions: Y.Z. and L.-X.W. conceived and designed the experiments; Y.Z., H.Z., F.W. performed the experiments; Y.Z. and L.-X.W. analyzed the data; L.X.W. contributed reagents/materials/analysis tools; Y.Z. wrote the paper.

Funding: The project was supported by The Project program of Key Laboratory of Food Nutrition and Safety, Ministry of Education, China (No. 2018006) and Hebei Province and School Science and Technology Cooperation Development Fund Project.

Acknowledgments: The authors acknowledge administrative and technical support given by Anjun Liu and Haiyu Ji.

Conflicts of Interest: The authors declare no conflict of interest.

\section{References}

1. Afzal, M.; Al-Hadidi, D.; Menon, M.; Pesek, J.; Dhami, M.S.I. Ginger: An ethnomedical, chemical and pharmacological review. Drug Metab. Drug Interact. 2001, 18, 159-190. [CrossRef]

2. Kumar, L.; Chhibber, S.; Harjai, K. Zingerone inhibit biofilm formation and improve antibiofilm efficacy of ciprofloxacin against Pseudomonas aeruginosa PAO1. Fitoterapia 2013, 90, 73-78. [CrossRef] [PubMed]

3. Vinothkumar, R.; Vinothkumar, R.; Sudha, M.; Nalini, N. Chemopreventive effect of zingerone against colon carcinogenesis induced by 1,2-dimethylhydrazine in rats. Eur. J. Cancer Prev. 2014, 23, 361-371. [CrossRef] [PubMed]

4. Ahmad, B.; Rehman, M.U.; Amin, I.; Arif, A.; Rasool, S.; Bhat, S.A.; Afzal, I.; Hussain, I.; Bilal, S. A Review on Pharmacological Properties of Zingerone (4-(4-Hydroxy-3-methoxyphenyl)-2-butanone). Sci. World J. 2015, 2015, 816364. [CrossRef] [PubMed]

5. Koch, W.; Kukula-Koch, W.; Marzec, Z.; Kasperek, E.; Wyszogrodzka-Koma, L.; Szwerc, W.; Asakawa, Y. Application of Chromatographic and Spectroscopic Methods towards the Quality Assessment of Ginger (Zingiber officinale) Rhizomes from Ecological Plantations. Int. J. Mol. Sci. 2017, 18, 452. [CrossRef] [PubMed] 
6. El-Baroty, G.S.; El-Baky, H.A.; Farag, R.S.; Saleh, M.A. Characterization of antioxidant and antimicrobial compounds of cinnamon and ginger essential oils. Afr. J. Biochem. Res. 2010, 4, 167-174.

7. Noori, S.; Zeynali, F.; Almasi, H. Antimicrobial and antioxidant efficiency of nanoemulsion-based edible coating containing ginger (Zingiber officinale) essential oil and its effect on safety and quality attributes of chicken breast fillets. Food Control 2018, 84, 312-320. [CrossRef]

8. Ye, Q.; Georges, N.; Selomulya, C. Microencapsulation of active ingredients in functional foods: From research stage to commercial food products. Trend. Food Sci. Technol. 2018, 78, 167-179. [CrossRef]

9. Zhang, Z.; Zhang, R.; Chen, L.; McClements, D.J. Encapsulation of lactase ( $\beta$-galactosidase) into K-carrageenan-based hydrogel beads: Impact of environmental conditions on enzyme activity. Food Chem. 2016, 200, 69-75. [CrossRef] [PubMed]

10. Kurozawa, L.E.; Park, K.J.; Hubinger, M.D. Effect of carrier agents on the physicochemical properties of a spray dried chicken meat protein hydrolysate. J. Food Eng. 2009, 94, 326-333. [CrossRef]

11. Wen, P.; Zhu, D.-H.; Wu, H.; Zong, M.-H.; Jing, Y.-R.; Han, S.-Y. Encapsulation of cinnamon essential oil in electrospun nanofibrous film for active food packaging. Food Control 2016, 59, 366-376. [CrossRef]

12. Loftsson, T.; Brewster, M.E. Pharmaceutical applications of cyclodextrins: Effects on drug permeation through biological membranes. J. Pharm. Pharmacol. 2011, 63, 1119-1135. [CrossRef] [PubMed]

13. Qiu, C.; Wang, J.; Fan, H.; Bai, Y.; Tian, Y.; Xu, X.; Jin, Z. High-efficiency production of $\gamma$-cyclodextrin using $\beta$-cyclodextrin as the donor raw material by cyclodextrin opening reactions using recombinant cyclodextrin glycosyltransferase. Carbohydr. Polym. 2018, 182, 75-80. [CrossRef] [PubMed]

14. Sá Couto, A.R.; Ryzhakov, A.; Loftsson, T. Self-Assembly of $\alpha$-Cyclodextrin and $\beta$-Cyclodextrin: Identification and Development of Analytical Techniques. J. Pharm. Sci. 2018, 107, 2208-2215. [CrossRef] [PubMed]

15. Pal, A.; Gaba, R.; Soni, S. Effect of presence of $\alpha$-cyclodextrin and $\beta$-cyclodextrin on solution behavior of sulfathiazole at different temperatures: Thermodynamic and spectroscopic studies. J. Chem. Thermodyn. 2018, 119, 102-113. [CrossRef]

16. Astray, G.; Gonzalez-Barreiro, C.; Mejuto, J.C.; Rial-Otero, R.; Simal-Gándara, J. A review on the use of cyclodextrins in foods. Food Hydrocoll. 2009, 23, 1631-1640. [CrossRef]

17. Ren, H.; Lyu, Y.; Li, X.; Zhang, S.; Ye, Y.; Li, D.; Mu, C. Preparation and characterization of dialdehyde $\beta$-cyclodextrin with broad-spectrum antibacterial activity. Food Res. Int. 2018, 111, 237-243. [CrossRef] [PubMed]

18. Sherje, A.P.; Dravyakar, B.R.; Kadam, D.; Jadhav, M. Cyclodextrin-based nanosponges: A critical review. Carbohydr. Polym. 2017, 173, 37-49. [CrossRef] [PubMed]

19. Škvára, J.; Nezbeda, I. Molecular dynamics study of racemic mixtures: Solutions of ibuprofen and $\beta$-cyclodextrin in methanol. J. Mol. Liq. 2018, 265, 791-796. [CrossRef]

20. Felt, O.; Carrel, A.; Baehni, P.; Buri, P.; Gurny, R. Chitosan as tear substitute: A wetting agent endowed with antimicrobial efficacy. J. Ocular Pharmacol. Ther. 2000, 16, 261-270. [CrossRef] [PubMed]

21. Schuerer, N.; Stein, E.; Inic-Kanada, A.; Ghasemian, E.; Stojanovic, M.; Montanaro, J.; Bintner, N.; Hohenadl, C.; Sachsenhofer, R.; Barisani-Asenbauer, T. Effects of chitosan and chitosan N-acetylcysteine solutions on conjunctival epithelial cells. J. EuCornea 2018, 1, 12-18. [CrossRef]

22. Felt, O.; Furrer, P.; Mayer, J.M.; Plazonnet, B.; Buri, P.; Gurny, R. Topical use of chitosan in ophthalmology: Tolerance assessment and evaluation of precorneal retention. Int. J. Pharm. 1999, 180, 185-193. [CrossRef]

23. Rosenthal, R.; Günzel, D.; Finger, C.; Krug, S.M.; Richter, J.F.; Schulzke, J.-D.; Fromm, M.; Amasheh, S. The effect of chitosan on transcellular and paracellular mechanisms in the intestinal epithelial barrier. Biomaterials 2012, 33, 2791-2800. [CrossRef] [PubMed]

24. Li, P.-H.; Lu, W.-C. Effects of storage conditions on the physical stability of d-limonene nanoemulsion. Food Hydrocoll. 2016, 53, 218-224. [CrossRef]

25. Botrel, D.A.; Rodrigues, I.C.B.; de Souza, H.J.B.; de Barros Fernandes, R.V. Application of inulin in thin-layer drying process of araticum (Annona crassiflora) pulp. LWT Food Sci. Technol. 2016, 69, 32-39. [CrossRef]

26. Rokka, S.; Rantamäki, P. Protecting probiotic bacteria by microencapsulation: Challenges for industrial applications. Eur. Food Res. Technol. 2010, 231,1-12. [CrossRef]

27. Sabulal, B.; Dan, M.; Kurup, R.; Pradeep, N.S.; Valsamma, R.K.; George, V. Caryophyllene-rich rhizome oil of Zingiber nimmonii from South India: Chemical characterization and antimicrobial activity. Phytochemistry 2006, 67, 2469-2473. [CrossRef] [PubMed] 
28. Singh, G.; Kapoor, I.P.S.; Singh, P.; de Heluani, C.S.; de Lampasona, M.P.; Catalan, C.A.N. Chemistry, antioxidant and antimicrobial investigations on essential oil and oleoresins of Zingiber officinale. Food Chem. Toxicol. 2008, 46, 3295-3302. [CrossRef] [PubMed]

29. Stella, V.J.; He, Q. Cyclodextrins. Toxicol. Pathol. 2008, 36, 30-42. [CrossRef] [PubMed]

30. Stoilova, I.; Krastanov, A.; Stoyanova, A.; Denev, P.; Gargova, S. Antioxidant activity of a ginger extract (Zingiber officinale). Food Chem. 2007, 102, 764-770. [CrossRef]

31. Wang, L.; Yang, S.; Cao, J.; Zhao, S.; Wang, W. Microencapsulation of Ginger Volatile Oil Based on Gelatin/Sodium Alginate Polyelectrolyte Complex. Chem. Pharm. Bull 2016, 64, 21-26. [CrossRef] [PubMed]

32. Szente, L.; Szejtli, J. Cyclodextrins as food ingredients. Trends Food Sci. Technol. 2004, 15, 137-142. [CrossRef]

33. Marques, H.M.C. A review on cyclodextrin encapsulation of essential oils and volatiles. Flavour Fragr. J. 2010, 25, 313-326. [CrossRef]

34. Wen, P.; Zhu, D.-H.; Feng, K.; Liu, F.-J.; Lou, W.-Y.; Li, N.; Zong, M.-H.; Wu, H. Fabrication of electrospun polylactic acid nanofilm incorporating cinnamon essential oil/ $\beta$-cyclodextrin inclusion complex for antimicrobial packaging. Food Chem. 2016, 196, 996-1004. [CrossRef] [PubMed]

35. Rakmai, J.; Cheirsilp, B.; Mejuto, J.C.; Simal-Gándara, J.; Torrado-Agrasar, A. Antioxidant and antimicrobial properties of encapsulated guava leaf oil in hydroxypropyl-beta-cyclodextrin. Ind. Crops Prod. 2018, 111, 219-225. [CrossRef]

36. Haiyan, G.; Lijuan, H.; Shaoyu, L.; Chen, Z.; Ashraf, M.A. Antimicrobial, antibiofilm and antitumor activities of essential oil of Agastache rugosa from Xinjiang, China. Saudi J. Biol. Sci. 2016, 23, 524-530. [CrossRef] [PubMed]

37. Cetin Babaoglu, H.; Bayrak, A.; Ozdemir, N.; Ozgun, N. Encapsulation of clove essential oil in hydroxypropyl beta-cyclodextrin for characterization, controlled release and antioxidant activity. J. Food Process. Preserv. 2017, 41, e13202. [CrossRef]

38. Rakmai, J.; Cheirsilp, B.; Torrado-Agrasar, A.; Simal-Gándara, J.; Mejuto, J.C. Encapsulation of yarrow essential oil in hydroxypropyl-beta-cyclodextrin: Physiochemical characterization and evaluation of bio-efficacies. CyTA-J. Food 2017, 15, 409-417. [CrossRef]

39. Aksamija, A.; Polidori, A.; Plasson, R.; Dangles, O.; Tomao, V. The inclusion complex of rosmarinic acid into beta-cyclodextrin: A thermodynamic and structural analysis by NMR and capillary electrophoresis. Food Chem. 2016, 208, 258-263. [CrossRef] [PubMed]

40. Rakmai, J.; Cheirsilp, B.; Mejuto, J.C.; Torrado-Agrasar, A.; Simal-Gándara, J. Physico-chemical characterization and evaluation of bio-efficacies of black pepper essential oil encapsulated in hydroxypropyl-beta-cyclodextrin. Food Hydrocoll. 2017, 65, 157-164. [CrossRef]

41. Joseph, J.J.; Sangeetha, D.; Gomathi, T. Sunitinib loaded chitosan nanoparticles formulation and its evaluation. Int. J. Biol. Macromol. 2016, 82, 952-958. [CrossRef] [PubMed]

42. Keawchaoon, L.; Yoksan, R. Preparation, characterization and in vitro release study of carvacrol-loaded chitosan nanoparticles. Colloid Surf. B Biointerfaces 2011, 84, 163-171. [CrossRef] [PubMed]

43. Matshetshe, K.I.; Parani, S.; Manki, S.M.; Oluwafemi, O.S. Preparation, characterization and in vitro release study of $\beta$-cyclodextrin/chitosan nanoparticles loaded Cinnamomum zeylanicum essential oil. Int. J. Biol. Macromol. 2018, 118, 676-682. [CrossRef] [PubMed]

(C) 2018 by the authors. Licensee MDPI, Basel, Switzerland. This article is an open access article distributed under the terms and conditions of the Creative Commons Attribution (CC BY) license (http://creativecommons.org/licenses/by/4.0/). 